IDEAS IN ECRLGGY AND EVILUTION 9: 19-23, 2016

doi:10.4033/iee.2016.9.5.e

(C) 2016 The Author. (C) Ideas in Ecology and Evolution 2016

Received 13 July 2016; Accepted 18 July 2016

Editorial

\title{
Some advice to early career scientists: Personal perspectives on surviving in a complex world
}

\author{
John P. Smol \\ John P.Smol (smolj@queensu.ca), Paleoecological Environmental Assessment and Research Lab (PEARL), Dept. \\ Biology, Queen's University, Kingston, Ontario, Canada, K7L 3N6
}

I began writing this paper with some trepidation as I can imagine many readers asking: What makes you an expert on providing advice to young scientists? I do not claim to have any special expertise in this area, other than the practical experience I have gained from mentoring a large number of young scientists over the last three decades. My ideas on this topic have been refined over the past few years when, after being awarded several teaching and mentoring awards, I began receiving invitations to provide talks and workshops focused on mentoring young scientists. To date, I have provided presentations on this topic on five continents, indicating broad interests in these issues. The impetus for this commentary was reinforced further when the Editor of Ideas in Ecology and Evolution recently listened to one of my presentations and invited me to provide this perspective.

The 13 points of advice outlined below summarize some of the main topics I have attempted to develop in my various workshops and presentations to young scientists. These points have evolved over time, and were modified following discussions with students and mentors. I certainly do not claim that any of them are highly original, but they represent what I believe to be practical suggestions and points for discussion.

1) Don't underestimate the value of what you are doing. If you are practicing sound science, then you are doing something worthwhile. Enthusiasm is an important catalyst, just as cynicism can be contagious.

Science and other forms of scholarship can and do make a big difference in the world, and we should never underestimate the significance of what we do. For a democracy to function effectively, it requires an educated and active citizenry, with a strong foundation in evidence-based policy. We have created complex problems that invariably require complex solutions. Science matters more now than it has ever before.

Sometimes it is easy for students and other early career researchers to lose focus by worrying that their work is unappreciated and only a tiny part of the "big picture". But this is how science functions. The history of science is full of research examples of how pieces of the puzzle were used to help make great discoveries and produce great new ideas. Sometimes this happens quickly, but it may also take decades. And great ideas can change the world.

When it comes to the type of science you choose to do, my general advice is to do something you love, not necessarily something that you think may have the biggest "pay off" (whatever that "pay off" may be). Passion and enthusiasm are key catalysts in research and in communicating your science to your colleagues and the public-at-large. An enthusiastic and passionate lab almost always produces a higher volume of impactful studies than other, less enthusiastic labs. If lab members get excited about discovery and research, and maintain an optimistic and enthusiastic outlook, the positivity is contagious and spreads through the lab and collaborators alike.

By the same token, cynicism can be just as infectious as enthusiasm. It is easy to fall into the trap of "no one cares about what I do, so why bother?" Beware of these traps. If you are doing good science, then you are doing something important. Period. As much as possible, seek out collaborators that also love what they do as this will accelerate progress and make the research that much more enjoyable. 
2) Time is our most important commodity. It is critical to learn to use it wisely.

Perhaps my biggest piece of practical advice is to get organized, as time rapidly becomes one's most precious commodity. We do not have the luxury of wasting it. I continue to be surprised at how much time some of my colleagues and students spend looking for documents or data files or field and lab equipment. My advice is to critically examine your organization system and invest the time that is needed to improve it (doing this early in your career is easier than doing it later). It might take a day or a week or longer, but I can assure you, your time investment will be paid back to you many times over.

The next step is to use your available time wisely. Scientists have many diverse demands and the most successful researchers have learned to use a system of triage to prioritize their tasks and to recognize that each task must have a timeline associated with it. Plan how to use your day wisely to meet your obligations and your goals. Moreover, as your career progresses, it is easy for most of your day to disappear with many other obligations that, although often supportive to the overall scientific process (e.g., administrative tasks), divert your attention from your core priorities. A system that protects time for basic research and reading and other related activities is critical. Re-evaluate your priorities and goals often; they will change over time. And leave time to reflect.

\section{3) The real challenge in science is asking appropriate questions. Big questions get big answers.}

In science our main focus is on getting answersanswers that can be defended against external criticism. But how much time do we spend formulating our questions? Is this not the most important part of the scientific process? I would argue that getting answers is often much easier than asking novel, relevant, or appropriate questions, and that we should spend much more time in making sure we ask the critical questions and in designing our projects to help answer these questions.

It is frankly easier to ask questions that may fall under what is sometimes referred to as the "reinforcement syndrome" or, less diplomatically, as "turning the crank" science. Examples include determining whether a study completed in one geographic location will have the same results in another location, or perhaps doing the same study using different organisms. Of course this type of work is both valuable and necessary: It is an integral part of most research programs and it pushes science forward. However, if you are an early career researcher, and if you have the choice between doing confirmatory science versus explanatory science, I encourage opting for the latter! At an early stage of your career, it is important to have "ownership" of some highly original ideas and studies, rather than contributing in a more incremental way to the overall scientific process. When given the opportunity, lead rather than follow. Putting in the extra effort to ask the most interesting and appropriate questions is where this process can begin, not after-the-fact.

Nonetheless, when we formulate our research questions, it is more important to choose ones that are answerable, rather than those that are simply interesting. This is not to say that there is shame in framing bold hypotheses - we should be framing bold hypotheses. What I am saying is that there is much shame in not using all of the available data and the basic findings of past studies to form new and bold hypotheses. Yes, it is important to try to "think outside the box", but beware of "thinking outside the warehouse!" Ignore other scientists' observations at your peril. Dare to challenge and dare to be wrong, but ideas must be constrained by reality and grounded on the foundation of past knowledge. Yes, it is better to ask an interesting question, but only if the interesting question is answerable. Research is about getting correct and defendable answers at the time the research was conducted. Of course the answers may not be correct or defendable in a decade or two. However, be glad if this occurs, as it shows that your original research has helped science move forward.

\section{4) Keep an open mind and interact with as broad a research community as possible.}

With the continued specialisation of science, it is often easy to fall into the trap of reading and interacting almost exclusively with people in our compartmentalized domains. There is some inevitability with this, with the increasing numbers of studies published, coupled with the growing trend of more specialised conferences, seminars, and journals. On top of this, we are all suffering from information overload.

Nonetheless, my experience shows that it is often very profitable to explore outside your "comfort zone" as often as possible. This is often where we get original ideas, learn about novel approaches and technologies, and make new connections.

Given the limited time we all have, it is hard enough to try and keep up with our own specialised areas of interest, let alone to explore other related disciplines. However, there are relatively simple ways to increase one's scope and perspective. For example, attending a wide-range of departmental seminars is a simple and inexpensive way - in both time and money - to learn about different disciplines and to expose oneself to new ideas or approaches. Similarly, if you are at a scientific conference, attend presentations and posters that are unrelated to your work. After all, a major function of conferences is to bring together diverse researchers in the hopes of making new connections. These are great 
venues to expand your network, to share and discuss different ideas, and to develop those big questions. Taking time to read scientific papers outside your direct area of expertise can also greatly increase your perspective and provide fertile ground for developing new research directions and finding collaborators in those fields. Share your ideas openly, and others will do the same.

\section{5) Don't set up artificial divisions in science.}

There are enough challenges in life and in doing science without making new, artificial problems. I see no advantage in defining and re-defining "camps" or in labelling researchers as being in "in the so-and-so camp" or as doing "only 'applied science' versus 'basic science'." Why not just agree that all good and honest science is important? No discipline has a monopoly on quality research. There is great work, poor work, and much in between across all scientific fields - strive to be in the former group.

It was never clear to me what function labels serve, although they often had a derogatory tone, perhaps implying a lack of impartiality, or that one "camp" is better than another. The artificial nature of many of these labels has always amused me as well. I will use a personal example to make my point. When I was hired by Queen's University as a limnology professor, my main area of research was studying the long-term development of lake systems from the time of the Ice Ages. What can be more esoteric than that? Clearly this would be classified as the most basic of fundamental research. So, for some time, I was "just doing esoteric research." However, soon after I was hired, a few of us began applying some of our paleoenvironmental approaches to studying acid rain and determining if and when lakes acidified and other socially and economically relevant questions. Somehow, in a period of about one week, my research program switched from being called "highly esoteric" to "highly applied." I have always argued that the main difference between "basic" and "applied" science is just a matter of time! What seems to be "basic" science one day can become "applied" science overnight.

The only division that truly matters is the one between good science and poor science. Any other divisions are unnecessary and distracting.

6) Be prepared for surprises. Our expectations are sometimes betrayed by observations.

As the Nobel laureate Richard P. Feynman (19181988) noted: "The first principle is that you must not fool yourself - and you are the easiest person to fool." Stated another way, don't get too emotionally attached to your hypotheses - this may cloud your judgment.
We are all guilty of this to a certain extent, but good scientists require the maturity to keep an open mind and to recognize when it is time to abandon some of our precious ideas should enough information come to light disputing them. The history of science is filled with anecdotes about scientists, some of them well known, who refused to abandon an idea, even after the accumulation of an enormous mountain of refuting studies.

As scientists, we have to constantly challenge our ideas with new data and observations. Doubt is the scientist's only certainty. This was astutely stated by another Nobel laureate, Max Planck (1858-1947), who concluded that "Science advances one funeral at a time."

\section{7) Learn to appreciate and benefit from the positive aspects of criticism.}

In many respects, science is the search for mistakes. Science is self-correcting and works by falsification and challenges. Criticisms and challenges are what advance science. Science is a marathon, rarely a sprint, and the oxygen that drives science forward is criticism. This can have negative implications for some, who (like me) are uncomfortable in contentious situations. However, as the Canadian ecologist Robert H. Peters (1946-1996) noted: “... we hone our theories and research until they are as keen and sharp as they may be. The whetstone against which we sharpen our tools is criticism." Always keep in mind that the main function of the peer review system is to improve the quality of the science upon which we all depend. There is no dishonour in being knocked down; there is only dishonour in not getting up again. Learn from your mistakes; we all make them.

Just as there are positive aspects to being criticized, there are positive ways to deliver criticism. Challenges and critical commentaries can and should be done in a constructive and helpful manner. Or stated more plainly: Anonymity is no excuse for being a jerk! When completing a peer review, think about how you would feel receiving that review. It is always easy to point out faults and limitations in a study, but why not go one step further and provide constructive suggestions on how their paper can be improved? I have been editing scientific articles almost my entire adult life and, in my experience, those who speak the loudest and most arrogantly rarely have the data to back up their ideas. Unsubstantiated criticism is often the last resort of the chronic under-achiever. There is a real and fundamental difference between strong opinions and important principles, even though the former may be heard much more loudly. Opinions don't mean very much in science-data matter. If you receive unsubstantiated criticism, remember that reviewers are not infallible, and that you can appeal decisions (with documentation) 
to editors, at least to good editors who are not scared of looking "weak" by disagreeing with a reviewer or admitting they made a mistake.

Peer review is not perfect, but it is the best system we have. My view is that you have a responsibility to engage in the peer review system in a constructive manner. The integrity of the peer review process is the linchpin of science. Do your part to make it better, not worse.

During your career you will undoubtedly read published papers that you believe are wrong based on some details or methodology or conclusions. With few exceptions, authors are often happy to discuss disagreements with you. This is part of the give-andtake of science. If you believe the problems are more fundamental and important enough to respond formally, then there are other avenues to explore disagreements, such as the Comment and Reply section supported by most scientific journals. Once again, there are collegial ways to disagree and to move science forward. It is important to keep the discussion courteous, professional, and constructive. Certainly starting a "whisper campaign" aimed at undermining a paper or the reputation of authors is the very opposite of professionalism. Only cowards resort to attacks where rebuttals are not possible. No serious researcher, interested in good science and advancing our scientific understanding, should resort to such behaviour. If people are talking about you behind your back, that says much more about them than it does about you.

\section{8) If you are going to cite or criticize a paper, at least have the courtesy to read it!}

With my work as an editor and as a scientist, I have this sense that our community has a growing problem of researchers citing and sometimes criticizing papers that they simply could not have ever read or thought deeply about. What appears to be happening more and more is that authors are re-citing other peoples' published interpretations of studies, without reading the original papers. This has always reminded me of the "telephone game" that young children sometimes play at parties: A story is whispered into the ear of one child, who then whispers the story into the ear of the next child in line, and so forth. By the time you get to the last child in the line, the story has changed so much that the original story is no longer recognizable.

The same phenomenon happens with scientific writing. Unless authors read the original documents, misconceptions and errors are "recycled" and often amplified in the literature. With every re-telling, the accuracy of the original findings is further altered. If you are going to cite a study, take the responsibility of reading it thoroughly and carefully and of thinking about it rigorously. Don't assume a previous author got it right.

\section{9) If nature (or circumstances) throws you a slow- moving softball, belt it out of the park! You might not get a second chance.}

I have often heard people talking (enviably) about some famous scientist, exclaiming "S/he is so luckys/he is always the first to get the major studies out." I tend to think that the amount of such "luck" amongst scientists is about equal. The reason for the difference is, in my view, two-fold.

First, some scientists are simply better prepared to recognize new ideas and connections. A scientist who has talked to lots of people from different fields and read multi-disciplinary studies is far more likely to make connections for some of the great ideas that we celebrate in science. As Louis Pasteur (1822-1895) adroitly noted: "In the fields of observation chance favors only the prepared mind."

Second, I believe a scientist's personality is equally important-successful scientists tend to be motivated to "get things done" and to persevere as challenges arise. Once they realize they have found something potentially important, they have the drive and the work ethic to complete the experiments or observations in a timely manner and, most importantly, to write them up for publication. Products (i.e., publications) are important, and being first (i.e., doing explanatory science) is more satisfying personally and professionally than being second (i.e., confirmatory science).

I am definitely not suggesting that scientists should rush to publish prematurely. I am, however, advising that once a researcher has solid and sound data and can make reasonable conclusions, then it is the appropriate time to publish. A major part of my interaction with students is to help them appreciate what their data can show. I keep asking them to stop telling me what our techniques or data can't show (aka the easy option); instead the goal is to determine what our observations can show and why this is important (aka the professional scientist option).

I have often heard the positive sounding word "perfectionist" to describe those who don't publish in a timely manner. I tend to wonder if perhaps "procrastinator" is not a better descriptor. Unlike many fine wines, data do not improve with the passage of time. There is no such thing as a "final study." Science is about making interpretations and decisions-justifiable decisions based on data. Your work is not done until it is published, and even then it is simply setting up for the next stage of investigation. Undoubtedly, with the passage of time, some scientists will find aspects of our work that needs revising. There is no shame in thisscience is (or should be) self-correcting. 


\section{0) Within reason, make your work known.}

The main purpose of science is to create knowledge that can be used by others. For knowledge to be used, people have to know it exists.

I am dumbfounded by scientists who proudly claim that they receive emails asking for copies of their work and they simply delete them, noting "If they want to read my work, they can find it themselves." Well, first, the statement is untrue - there are many regions of the world that do not have unlimited access to journal subscriptions. But second, after all the work one goes through to develop hypotheses, get the funding, do the science, write it up, submit it to a journal and go through the review process, why would you not want to make your work as accessible as possible? How difficult is it to press "Reply and Attach"?

I would argue that passive self-promotion of your work is also desirable. Some of this is easily accomplished by, for example, maintaining a personal web site with an updated list of your publications, setting up a Google Scholar web page, and subscribing to some of the social media sites that cater to researchers (such as ResearchGate). Also, sending pdfs of your research to close colleagues as papers get published ensures that they at least are knowledgeable of your work.

11) Communication of our research should not end in the classroom, laboratory, or at campus or conference boundaries.

Most scientists are quite effective at communicating their work via peer-reviewed publications and conference presentations, but are less effective at explaining their results to politicians, policy makers, and the public-at-large. Non-scientists deserve to know what we are doing and why science is important. After all, in most cases, it is their tax dollars that are funding the work in the first place! Scientists often complain that funding is poor, but at times I wonder how we still get funding at all, given our generally poor communication with the general public. Make the time to explain your results in lay terms, offer to give talks at schools and local clubs, and engage media in your work. By effectively and regularly communicating the results of our research, we can also impart knowledge and experience concerning the "culture of science" and/or other forms of scholarship (something still sadly lacking in some media discussions and therefore the public's perception of what goes on in universities and other institutes). Show by example that research is critically important to society and that researchers can influence political and other decisions.

When we are communicating with the public, we must choose our words carefully. For example, one of my particular peeves is the commonly used term "curiosity-based research." Now, before I continue, I stress that I have consistently championed the importance of basic or fundamental research, noting that it is the foundation of applied research. My concern is with the impression the general public has when they hear "curiosity-based research." I suspect they envision a privileged scientist away in some exotic country doing what most would think of as a self-indulgent academic hobby. Why not call it "basic research" or "fundamental research"? Words are important-we must choose them very carefully.

\section{2) Scientists have the responsibility to communicate their findings, even if they are "unpopular".}

Researchers will, at times, undoubtedly reach conclusions that may be unpopular with certain industries, political parties, or the public. Certainly in my field of environmental science, I am almost always at odds with various industries, politicians, or their entourages (e.g., lobby groups, journalists and columnists with specific agendas, etc.). Yes, some of these interactions can be unpleasant, but it is no excuse to retreat. I worry about the growing threat of self-censorship, namely that it is easier simply to fade into the background and not engage. This leaves an information vacuum that allows vested interest groups to control the policy agenda. There is serious responsibility that comes with the privilege of doing science, and that is to communicate our findings, whether they are popular or not, as there is much at stake when accurate information fails to reach the public.

And yes, sometimes you have to throw stones at giants.

\section{3) Research is fun.}

And finally, always remember, research is fun...I try to laugh out loud with my students at least once a day! (Actually they are mainly laughing at me).

\section{Acknowledgements}

I would like to thank the large number of colleagues who thoughtfully read earlier drafts of this paper and provided many useful comments. 